\title{
La contribución del método etnográfico al registro del dato epidemiológico. Epidemiología sociocultural indígena quechua de la ciudad de Potosí
}

\author{
The contribution of the ethnographic method to the \\ register of the epidemiological data. \\ Quechua aborigine sociocultural epidemiology \\ of Potosí city
}

Susana Ramírez Hita ${ }^{1}$

${ }^{1}$ Licenciada en Antropología Social. Doctora en Antropología Social y Cultural, (especialidad Antropología de la Medicina). Investigadora adscripta del Programa de Antropología y Salud, Instituto de Ciencias Antropológicas, Facultad de Filosofia y Letras, Universidad de Buenos Aires (UBA); Argentina. susanahita@yahoo.es
RESUMEN Este artículo pretende dar a conocer la utilidad del método etnográfico para los registros epidemiológicos. A través del ejemplo de la ciudad boliviana de Potosí, se muestra cómo los datos epidemiológicos que servían de base para la implementación de políticas y programas sanitarios, no representaban la realidad. Se destacan los límites de la técnica de encuesta, y de los registros sustentados exclusivamente con metodología cuantitativa.

A partir de un registro de epidemiología sociocultural se rescatan los saberes de todos los representantes de los diversos sistemas de atención a la salud que son reconocidos por los habitantes de la ciudad, con el objetivo de detectar las problemáticas de salud pública más importantes de Potosí.

PALABRAS CLAVE Antropología Cultural; Población Indígena; Políticas Públicas de Salud; Bolivia.

ABSTRACT This article intends to show the usefulness of the ethnographic method for epidemiological registers. Through the example of the Bolivian city of Potosí, it is shown how the epidemiological data which served as a basis for the implementation of sanitary policies and programs did not represent reality. We highlight the limits of the survey technique and the registers sustained exclusively with quantitative methodology.

From the sociocultural epidemiology register, we gather the knowledge of all the representatives of the different systems of health attention recognized by the inhabitants of the city, in order to detect the most important problems in public health in Potosí

KEY WORDS Anthropology, Cultural; Indigenous Population; Health Public Policy; Bolivia. 


\section{¿QUÉ VENTAJAS TIENE EL MÉTODO ETNOGRÁFICO PARA EL ABORDAJE EPIDEMIOLÓGICO?}

A través de este artículo se intenta mostrar -con el ejemplo de los datos epidemiológicos de una ciudad boliviana- cómo la complejidad de la realidad sanitaria no puede ser abordada en exclusividad a través de datos numéricos, sino que los aspectos económicos, políticos, ideológicos y socioculturales, no reducibles a ellos, son necesarios para detectar y analizar las patologías y las problemáticas de mayor incidencia en una población determinada. En algunas regiones y países los datos epidemiológicos no representan las causas reales de morbimortalidad de las diversas poblaciones (a), porque el registro epidemiológico se realiza exclusivamente sobre las patologías biomédicas y desde los centros de salud.

El dato epidemiológico es de suma importancia por tratarse del primer paso (en muchos casos, el único) a tener en cuenta a la hora de implementar futuros programas y políticas de salud, que ayuden a mejorar los índices de morbimortalidad. Uno de los aspectos que repercute en una menor eficacia de los programas de salud que se implementan es, precisamente, la inadecuación de muchos de ellos a la realidad en la que se llevan a cabo.

Son numerosos los factores que influyen; entre ellos y como veremos más adelante, uno de los mayores problemas es la manera en que se registran los datos.

Dar cuenta de todos los aspectos que tienen influencia sobre las causas de morbimortalidad implica no solo conocer los datos de los registros epidemiológicos realizados desde los servicios estadísticos de salud, sino también de las causas de morbimortalidad, según los diversos sistemas de atención a la salud y, por supuesto, de la población en general (b). Este conocimiento implica una diversidad de patologías, que amplía las reconocidas por la Organización Mundial de la Salud (OMS), y que es necesario que sean registradas, ya que son habitualmente reconocidas, incluso por el propio personal sanitario que conoce y utiliza también sistemas alternativos para tratar patologías populares.
A lo largo del trabajo se intentará demostrar la importancia del método etnográfico para la recolección del dato epidemiológico y la necesidad de la convivencia con los diversos grupos sociales para poder obtener datos "reales" para los registros estadísticos; como también demostrar la importancia de realizar diagnósticos de salud desde una metodología cualitativa que implique la recolección del dato a través de la etnografía, pero para ello debemos aclarar primero qué entendemos por etnografía en el sentido estricto del término.

\section{LA ETNOGRAFÍA COMO PRIMER PASO PARA UN BUEN REGISTRO}

El método etnográfico implica una manera específica de acercarse a la realidad, con el fin de obtener información en profundidad sobre la temática que se desea abordar. Según Hammersley y Atkinson:

\footnotetext{
...el etnógrafo o la etnógrafa participa [...] de la vida cotidiana de personas durante un tiempo relativamente extenso, viendo lo que pasa, escuchando lo que se dice, preguntando cosas; o sea, recogiendo todo tipo de datos accesibles para poder arrojar luz sobre los temas que él o ella han elegido estudiar. La etnografía es la forma más básica de investigación social... (2 p.15)
}

Ello conlleva, por un lado un tiempo prolongado de convivencia con el grupo social que se decide investigar y, por otro, una relación con los sujetos de estudio que trasciende la relación de observador/observado, para pasar a una relación entre observación y transformación (3). Partiendo de esta interacción entre observador/observado, entenderemos el hecho de que los valores del investigador influyen en la investigación, por lo cual "los hallazgos están mediados por los valores" (4 p.127).

Cuando la convivencia con el grupo es prolongada, aparecen otros factores que van a condicionar el dato que se registra. Aquí, el dato, al contrario que en la técnica de la encuesta -en donde no interesa el sujeto en sí, sino el dato que aporta- no es impersonal. En la información 
obtenida a través del método etnográfico, a diferencia de la que se consigue a través de la metodología cuantitativa, los sujetos -y no los datos abstraídos de la realidad- se constituyen en elemento central. De esta manera, precisamente, los datos construidos a partir de la dinámica procesual de la vida cotidiana en la que está inserto el etnógrafo, son mucho más ricos y complejos, responden con más rigor a la realidad $y$, por lo tanto, son más fiables que aquellos que se han descontextualizado de sus marcos de origen.

Sin embargo, la existencia de un tiempo de convivencia prolongado con un grupo social no tiene porqué significar la aplicación de la técnica de observación participante. Hay que distinguir la etnografía o el método etnográfico de las técnicas que se utilizan dentro del mismo. Es frecuente, pese a las diferencias, la confusión entre las técnicas de observación participante y observación, con la etnografía.

Por técnica de observación participante entendemos aquella en la que el mismo cuerpo del investigador es parte importante de la investigación; es decir, se puede convivir con mujeres lavanderas y, sin embargo, no lavar nunca ropa. Al registrar que lavar ropa puede generar una enfermedad, el registro del dato puede efectuarse mediante la técnica de observación o a través de la entrevista, pero, si lavamos ropa, podremos sentir en nuestro cuerpo el dolor que se experimenta cuando alguien tiene las manos en agua fría durante mucho tiempo. El dato registrado tiene, en este caso, un valor diferente al resultado de la observación del cómo y cuándo otros realizan una acción. Y no tan solo es importante la percepción del dato a través del cuerpo del investigador sino, sobre todo, comprobar cómo cambia radicalmente la relación que se mantiene con los sujetos o con el grupo de estudio cuando uno efectúa la misma actividad que los "otros". A este respecto, pondremos otro ejemplo que servirá para aclarar el alcance de la técnica de observación participante. Mientras realizaba trabajo de campo sobre la calidad de atención en los hospitales públicos del Altiplano -años después de desarrollar esta investigación- tuve que ser ingresada en un hospital para ser intervenida quirúrgicamente. Debido a esa internación, los datos obtenidos previamente a través de las técnicas de entrevista y observación cobraron un sentido radicalmente diferente, a partir del momento en que mi cuerpo entró en juego y asumió un papel central a la hora de entender cómo era la calidad de atención dentro de los hospitales públicos bolivianos.

En consecuencia, a lo largo de este artículo, cuando se haga referencia a la utilización de la técnica de observación participante en todos los sistemas médicos, se hará referencia también al hecho de haber sido parte activa como paciente, en la realización cotidiana de las actividades de los hogares o, entre otras, en la participación en ceremonias rituales.

La técnica de observación participante no necesariamente supone emplear un tiempo prolongado en campo ya que puede realizarse en un período breve de tiempo. Sin embargo, sí conlleva el cuerpo del investigador en acción, entendido como "el cuerpo situado en el sentir" o "el cuerpo sintiendo" que proporciona un nivel de percepción del dato que va mucho más allá de la información que cabe recoger a través de las técnicas de metodología cualitativa, que acabamos de citar.

En cualquier caso, ha de quedar claro que una investigación puede ser realizada a través del método etnográfico, mediante técnicas que no sean la de observación participante, usando, por ejemplo, la técnica de observación, la entrevista, el grupo focal o la historia de vida.

En definitiva, el método etnográfico se caracteriza por el conocimiento del "otro" a partir de la permanencia prolongada en el grupo de estudio y del compromiso, establecido en términos éticos y de relaciones humanas, que se establece con los sujetos de dicho grupo de estudio, y una de sus principales diferencias a nivel metodológico es que dentro de este tipo de investigación el investigador "se considera a sí mismo como el elemento de observación por excelencia" (3 p.31). Partimos de que:

...el conocimiento consiste en aquellas construcciones acerca de las cuales hay consenso relativo [...] entre aquellas personas competentes [...] para interpretar la sustancia de la construcción. (4 p.134)

Al situar como eje de la investigación el entender y reconstruir las construcciones de los 
sujetos, y esto incluye, sin duda, al investigador, partimos de que los datos son siempre socialmente construidos.

Así pues, cuando nos referimos a etnografía nos remontamos al comienzo de la disciplina antropológica, cuando la mayoría de los antropólogos convivían con los grupos que estudiaban (por largos períodos de tiempo). Ésta siempre ha sido una característica del quehacer antropológico y ha marcado una identidad particular que ha hecho al antropólogo diferente al resto de los profesionales de las ciencias sociales. Debido a múltiples factores -el más importante, sin duda, la oferta laboral-, la etnografía se está convirtiendo cada vez más en una suma de técnicas de metodología cualitativa que están siendo utilizadas en períodos de tiempo tan cortos que no deberían ser denominadas etnografías (5) (c).

Convivir con los grupos en estudio permite obtener, no solo una mejor calidad en la recolección del dato (calidad entendida como fiabilidad del dato registrado), sino que también permite al antropólogo poder entender con mayor profundidad por qué suceden los hechos de la manera en que suceden. Mientras que el epidemiólogo alerta sobre una realidad determinada (cólera, suicidio, etc.), el antropólogo dirá el porqué de lo que está aconteciendo en un grupo determinado $(6,7)$.

En definitiva, lo que permite el método etnográfico es poder dar cuenta de las articulaciones que se dan entre las representaciones y las prácticas. Ya que una cosa es lo que los sujetos sociales dicen hacer (d) y otra es lo que hacen. La observación de las prácticas pasa a ser la mejor manera en la obtención del dato $y$, sin duda, la técnica a través de la cual el registro del dato es el más fiable es la técnica de observación participante, mediante la cual el antropólogo participa del día a día del grupo que desea estudiar.

Conocer y analizar la articulación que se establece entre representaciones y prácticas sociales es el elemento fundamental para poder diseñar políticas y programas de salud eficaces y que incidan realmente en cambios de los grupos involucrados, siempre con el respeto a las formas de entendimiento y significado de la salud, la enfermedad y la muerte que tienen las diversas culturas y los distintos grupos sociales.
A fin de poder exponer con mayor claridad la argumentación sobre la utilidad de incorporar el método etnográfico a los registros epidemiológicos, usaremos como ejemplo la ciudad boliviana de Potosí, poblada en su mayoría por indígenas quechuas.

\section{IDENTIDAD ÉTNICA Y RELIGIOSA: LA INFLUENCIA EN LA RECOLECCIÓN DEL DATO}

Uno de los elementos centrales para poder entender cómo son registrados los datos en un contexto determinado es el análisis de la relación existente entre el dato epidemiológico, el personal sanitario y la población. Partir de las diferencias y heterogeneidades más que de la homogeneidad, implicaría tener en cuenta tres categorías: grupo étnico, identidad y religión. La manera más apropiada para poder incorporar estas categorías al registro del dato es realizar una etnografía que pueda dar cuenta de estos aspectos.

En el caso del altiplano boliviano, por ejemplo, encontramos que una mayoría del personal sanitario es de origen indígena, quechua o aymará. Sin embargo, la mayoría de los trabajadores de salud (e) que ejercen en las ciudades se autodefinen como mestizos. Más allá de que hablen o no la lengua aymará o quechua, y que practiquen su cultura, se autodefinen como mestizos por el hecho de vivir en la ciudad, de manera que asumen una equivalencia ciudad = mestizo, es decir, transformando su identidad a la mestiza, menos estigmatizada que la categoría de indígena, relacionando este término con un mayor estatus social. Habitualmente el personal sanitario que se autodefine como mestizo (siendo indígena), suele ser el más discriminador con la población indígena rural que es, en definitiva, la identidad de la que desean separarse. Ello lleva muchas veces a la negación de su propia cultura y a partir de ahí, a un peor trato al paciente de origen indígena. En la mayoría de los casos, ello va unido a la negación de la existencia de ciertas patologías populares y al no reconocimiento de ciertas prácticas médicas tradicionales. Este hecho está influenciado por la identidad anterior y posterior del sujeto social, pero también por la 
formación médica que suele ser más discriminatoria y estricta en algunos países latinoamericanos que en los países centrales. Tal y como menciona un médico con relación a la formación médica en Bolivia: "la enseñanza que nos dan es como a los militares y nos hacen negar todo lo que nuestros abuelos siempre han hecho". Sin duda, ello influye en la rigidez con la que se comportan en el ejercicio de su práctica profesional.

Este aspecto étnico incide en la forma de entender (al "otro"), de diagnosticar y de atender al paciente. Las trayectorias individuales están influenciadas por la identidad y la religión a la cual pertenecen. A modo de hipótesis, planteamos que estos aspectos influencian el registro del dato. La religión a la cual pertenece el profesional sanitario también tiene consecuencias en el diagnóstico de las enfermedades o padecimientos, así como en la manera de entender la causa por la cual es producida la enfermedad. La medicina no queda ausente de las influencias ideológicas de los sujetos concretos que ejercen su práctica.

\section{EL MÉTODO ETNOGRÁFICO}

La decisión de utilizar un método etnográfico para la realización de un diagnóstico de salud, que involucre el conocimiento de las problemáticas más importantes de salud pública de una población determinada, tiene que ver con una convicción teórica y metodológica sobre la importancia de este método en la recolección del dato.

El ejemplo que se expondrá para sustentar esta argumentación es la ciudad de Potosí, centrado en una investigación realizada durante los años 2004 y 2005 (8). La investigación consistió en un diagnóstico de salud dirigido a conocer las problemáticas de salud pública más importantes para encarar programas y políticas acordes con la realidad. Para ello se realizó, entre otros aspectos, un registro etnoepidemiológico, al mismo tiempo que se analizaban las falencias del sistema sanitario en el registro del dato. En el análisis del material se llegó a la conclusión de que el dato estadístico es acotado y limitado si no es acompañado de metodología cualitativa que pueda dar cuenta del porqué de los padecimientos y enfermedades que aparecen en un contexto determinado.
El aporte del método etnográfico en esta investigación fue conocer una realidad que no aparecía en los datos epidemiológicos del país y, a su vez, comprobar que las causas de las problemáticas de salud pública más importantes tenían que ver con la situación política, socioeconómica y cultural, y no exclusivamente con aspectos sanitarios.

La investigación se inició en la ciudad de Potosí a comienzos del año 2004 dentro de un proyecto realizado por la Fondazione Angello Celli per una Culture della Salute, financiado por la Unión Europea (Programa @lis), cuyo fin era capacitar al personal de salud de atención primaria a través de educación a distancia. El objetivo principal de la investigación era indagar sobre cuáles eran las necesidades del personal sanitario a través del conocimiento de su realidad y los requerimientos que la comunidad demandaba en cuanto a un mejoramiento en la formación del personal de los centros de atención primaria.

El método etnográfico pretendía dar cuenta de las problemáticas más importantes de salud de la ciudad de Potosí a través de las prácticas y representaciones del personal sanitario de los centros de atención primaria, así como de las representaciones y las prácticas de los terapeutas tradicionales, los pastores evangélicos y las madres quechuas (representantes de los distintos sistemas de atención a la salud). Para ello, era imprescindible vivir en la ciudad y al mismo tiempo convivir con los distintos actores para poder obtener los datos necesarios y entender de esta manera cuáles eran las dinámicas que hacían que esta ciudad tuviese la esperanza de vida más baja del país con un promedio de 57 años (9). Comencé alojándome en una vivienda (tipo conventillo) en el centro de la ciudad, en la que vivían varias familias quechuas, instaladas en distintos cuartos con un patio central.

Vivir el día a día de la ciudad me permitió observar los mercados y ver las deficientes condiciones higiénicas de los mismos: carne, frutas y verduras colocadas en el suelo, venta de productos alimenticios caducados (f), pollo en mal estado al que se le pone lavandina para camuflar el mal olor y el color, o lácteos y pasteles con merengue que pasaban largas horas en la calle, sin protección, al intenso sol del altiplano. Productos, todos ellos, que son permanentemente consumidos por la población. 
Al comer en los mercados de la ciudad, lugar muy frecuentado por sus habitantes por su bajo costo, comencé a padecer infecciones intestinales al igual que la mayoría de la población. La diarrea, en Potosí, es uno de los padecimientos más comunes, tanto en niños como en adultos, llegando a ser una de las principales causas de muerte infantil.

La ciudad es minera, hecho que repercute en la contaminación ambiental y también de las aguas. Potosí no posee agua potable y en muchas viviendas el agua no se hierve, ni se usa lavandina para desinfectarla. Esto hace que los habitantes padezcan reiteradamente graves problemas intestinales.

El primer acercamiento a los servicios sanitarios se produjo con motivo de la visita al hospital público y a los centros de atención primaria de la ciudad, que en el año 2002 contaba con una población de 145.057 habitantes (10). Al visitar los centros de salud, se presentó el proyecto al personal sanitario. En un principio se realizaron entrevistas grupales a los equipos de salud de cada uno de los centros (g). El objetivo de estas entrevistas era conocer cuáles eran las causas de consulta más frecuentes en los centros de salud y cuáles eran las causas más frecuentes de enfermedad y muerte en los barrios, estuvieran o no estas causas registradas en los datos epidemiológicos. A partir de este primer acercamiento se comenzó a detectar que el personal sanitario tenía un conocimiento de las causas de enfermedad y muerte diferente al que quedaba registrado en las planillas enviadas al Servicio Departamental de Salud (SEDES) y al Servicio Nacional de Información en Salud (SNIS).

Mientras se realizaba el trabajo de campo se iban revisando y analizando los datos epidemiológicos a nivel nacional, departamental y de la ciudad de Potosí, lo que permitió comprobar que únicamente las patologías infantiles representaban las principales causas de muerte que se acercaban a la realidad.

$\mathrm{Al}$ cabo de dos meses de recorrer los centros de salud y de trabajar con los equipos -observando los consultorios, visitando las casas en los diversos barrios con las trabajadoras sociales, etc., y haciendo vida social con el personal sanitario (asistiendo a bodas, bautizos, entierros, etc.)-, se organizaron cinco grupos focales (h) con todos los profesionales que trabajan en los centros (un grupo focal con las enfermeras, otro con las trabajadoras sociales, otro con los médicos, otro con los Responsables Populares de Salud y otro con las auxiliares de enfermería). Cada grupo focal incluía de 14 a 18 profesionales, con participación de casi todo el personal sanitario que trabajaba en los centros públicos de atención primaria de la ciudad. Esta técnica fue utilizada con el fin de trabajar sobre las problemáticas que afectaban al personal sanitario en su práctica profesional, y dejando que ellos fueran quienes plantearan los cursos de capacitación necesarios para mejorar sus condiciones laborales y su relación con la comunidad.

Como no era posible observar en profundidad todos los centros de atención primaria, ni toda la población, se seleccionó un barrio que no estuviera a las faldas del Cerro Rico, ya que todas las investigaciones se realizaban habitualmente en esos barrios. Se seleccionó un barrio del centro de la ciudad mediante el criterio de que el centro de salud que pertenecía al barrio y abarcaba una población de diez mil habitantes, atendiera tanto población de origen rural como urbana, ya que la ciudad de Potosí posee una gran movilidad campo-ciudad. Gran parte de la población viene de las comunidades rurales a trabajar una temporada en las minas de la ciudad o a vender ciertos productos; y suelen regresar al campo en la época de cosecha. La selección también fue hecha porque la mayoría de sus habitantes eran mineros y comerciantes, las dos profesiones más comunes.

La elección del barrio (i) implicó comenzar con un mes de observación en el interior del centro de salud seleccionado, realizando el día a día del centro, observando la relación médico/paciente en el interior del consultorio del médico, con la enfermera, la auxiliar de enfermería, la trabajadora social, es decir, con cada uno de los miembros que trabajaban en el centro; y conversando en la sala de espera con los pacientes que Ilegaban al puesto de salud para atenderse, la mayoría mujeres y niños. De estas mujeres, se seleccionaron diez, con el criterio de que fueran indígenas quechuas, de origen rural y citadino. También fueron seleccionadas en base a la categoría de religión, de manera que se eligieron mujeres de religión andina, católica y evangélica, las tres religiones más importantes de la ciudad (tres mujeres de religión evangélica, cuatro de religión católica y tres de religión andina) (j). 
Estos criterios de selección se fundamentaron en investigaciones anteriores realizadas en otras culturas $(12,13)$, en donde se demostró la importancia de la religión en el significado que conceden los sujetos sociales al diagnóstico, la enfermedad, la atención al padecimiento y el significado dado a la muerte.

Se efectuó una entrevista (k) a cada una de las mujeres seleccionadas y se visitaron reiteradamente sus casas $y$, a partir de este acercamiento, se pudo conocer y observar algunos itinerarios terapéuticos que eran realizados en el interior de estas familias (I). Las mujeres facilitaron el acercamiento a los terapeutas tradicionales más conocidos del barrio y a los pastores evangélicos (los pastores más frecuentados para sesiones de sanación y prevención de enfermedades y padecimientos, con los que se trabajó con mayor profundidad fueron dos) lo que permitió ver cómo eran atendidos los enfermos por estos pastores, no solo en la iglesia sino también en el interior de las casas y observar cómo las visitas a los puestos de salud eran casi en exclusiva para aquellas patologías que cubría gratuitamente el programa del Seguro Universal Materno Infantil (SUMI).

Mientras recurrían a los servicios médicos, eran consultados paralelamente otros sistemas de atención a la salud: religioso, tradicional, autoatención (m). La decisión de combinar ciertos sistemas dependía de si la familia formaba parte de la religión evangélica, católica o andina. Los itinerarios y las maneras de entender la enfermedad y sus causas variaban a pesar de que todas las familias pertenecían a un mismo grupo étnico: indígenas quechuas. De esta manera fue posible observar cómo la pertenencia a la identidad de un grupo étnico no podía explicar por sí sola las realidades más complejas que envuelven la toma de decisión de los sujetos sociales a la hora de recurrir a uno u otro sistema de salud.

Al mismo tiempo se realizó observación en todos los sistemas médicos que aparecían como lugar de consulta y atención de enfermedades y padecimientos de las familias. Se visitaron reiteradamente iglesias evangélicas de diversas denominaciones $(n)$, pudiendo observar las sesiones de sanación y los cultos de evangelización; del mismo modo se trabajó en el interior de los consultorios de los terapeutas tradicionales, seleccionando entre ellos a los dos más visitados. Con Don Felipe (o) fue posible presenciar con más asiduidad sus sesiones de sanación, que muchas veces se realizaban en la cima de los cerros, en los distintos lugares donde la persona se había enfermado -cuando se trataba, por ejemplo, del susto $(\mathrm{p})$ - o en el interior de las casas de los enfermos.

Después de más de seis meses de trabajo de campo se seleccionaron dos familias para poder hacer una observación más detallada de las prácticas en torno a la atención de los padecimientos y enfermedades en el interior de los hogares. La selección se realizó en base al criterio de campo-ciudad, por la situación socioeconómica y por la profesión que ejercían la mayor parte de sus miembros.

En la familia Pérez todos los hombres trabajaban en la mina y las mujeres lavando ropa (q). La selección de esta familia tenía que ver, junto con las categorías mencionadas, con el número de personas que habitaban la casa. Cada cuarto es habitado por una familia nuclear (padre, madre e hijos, alrededor de unos 5 miembros) y en la casa, además de todos los miembros de la familia Pérez (compuesta por cuatro familias nucleares con diez niños), se alquilaban dos cuartos en donde vivían otras familias y un cuarto donde alojaban a personas del campo que venían un corto tiempo a la ciudad. Es decir, que la casa era habitada por una treintena de personas de la familia, más los visitantes. Las mujeres de la casa eran de distintas generaciones y ello permitía observar cómo influía la edad en los cambios de prácticas con respecto a la prevención y la atención en los casos de enfermedad.

De la misma manera, la familia Jiménez, comerciantes de origen citadino, poseía más o menos el mismo número de personas en la casa, mujeres de distintas generaciones y un cuarto en el que alojaban a gente del campo. Ello permitía observar las prácticas en torno a la salud tanto de la población rural como de la urbana. La familia Jiménez se diferenciaba en que sus miembros eran comerciantes citadinos, con un poder económico algo más elevado, en tanto que algunas de las mujeres quechuas de la familia iban a la universidad. 
Esta selección posibilitaba la observación de prácticas de salud dentro de un mismo grupo étnico y la observación de las diferencias de clase social, situación socioeconómica, diferencias entre población del campo y de la ciudad y diferencias entre las distintas generaciones de mujeres.

En las casas recibían visitas frecuentes de terapeutas tradicionales del campo y de la ciudad, hecho que facilitó aún más la observación sobre las prácticas en torno a la salud.

La convivencia con las familias permitió seguir los itinerarios terapéuticos de aquellas enfermedades y padecimientos que iban apareciendo en el día a día: diarreas, infecciones intestinales, susto, amartelo, dolor de espalda, de cabeza, diversos accidentes, brujería, problemas de alcoholismo, sobreparto, embarazos no deseados, intentos de aborto, violencia doméstica, gripes, resfríos, orejo, estómago vacío, etc., (r). Es decir, se pudieron observar los itinerarios (s) tanto de patologías biomédicas como de patologías populares, observando la importancia de estas últimas en las causas de muerte otorgadas por la población.

La técnica de entrevista permitió registrar las representaciones de los distintos actores sociales que convergían en torno a nuestra problemática. Las entrevistas fueron semiestructuradas, siempre abiertas a la aparición de nuevas preguntas de acuerdo con el contexto en que éstas se efectuaban. Se realizaron un total de 37 entrevistas semiestructuradas, todas en idioma español.

A esto se sumaron entrevistas grupales en cada centro de salud (14 centros de salud urbanos y 3 centros rurales, aledaños a la ciudad de Potosí), destinadas a conocer las problemáticas de cada centro y de la población que atienden, los datos sobre las patologías más frecuentes en cada área y las representaciones del personal sanitario sobre los otros sistemas de salud no biomédicos.

Las entrevistas se llevaron a cabo en tres espacios bien diferenciados, que abarcaban los diferentes sistemas médicos que se encuentran en la ciudad de Potosí. Los informantes fueron seleccionados de la siguiente manera:

a) En el sistema biomédico: 17 entrevistas grupales en todos los centros de salud. Una entrevista grupal en el hospital con dos miembros de Willaqkuna (proceso de Salud Intercultural que se llevaba a cabo en el Hospital Daniel Bracamonte de la ciudad de Potosí), y dos entrevistas a las farmacias del barrio seleccionado, con la intención de ver si la farmacia era un primer nivel de atención para la población del barrio.

b) En el sistema médico tradicional: los informantes fueron seleccionados de acuerdo con los cargos que ocupaban dentro de las instituciones tradicionales y entre los terapeutas tradicionales que nombraban los habitantes del barrio. Se realizaron seis entrevistas individuales a tres terapeutas tradicionales. El objetivo de estas entrevistas era el conocimiento de las patologías populares, el conocimiento de los procesos de salud/enfermedad/atención de este sistema médico, y las representaciones de los terapeutas tradicionales sobre la biomedicina, y más en concreto del personal sanitario de los centros de atención primaria.

c) En el sistema de autoatención: se realizaron diez entrevistas a diferentes madres habitantes del barrio seleccionado, todas pertenecientes a estratos socioeconómicos bajos. Tres de estas entrevistas fueron grupales, con todas las mujeres del grupo familiar (normalmente tres generaciones). La mayor parte de la información sobre este sistema médico fue obtenida a través de conversaciones informales mantenidas en las charlas cotidianas.

d) En el sistema médico religioso: se realizaron tres entrevistas a representantes de salud de las iglesias católica y evangélica, ambas pertenecientes al barrio seleccionado: un representante de la iglesia católica de Potosí, un pastor y una pastora evangélica.

Con la observación de todos los sistemas médicos (religioso, biomédico, tradicional y de autoatención), tanto desde las prácticas que se realizan en su interior (en la prevención, en el diagnóstico y la atención de enfermedades y padecimientos), como el seguimiento de los itinerarios terapéuticos, se pudo observar y analizar con mayor detalle el sistema de autoatención, en el que convergen todas las formas de atención a la salud. 


\section{EL REGISTRO EPIDEMIOLÓGICO}

El registro epidemiológico de la ciudad de Potosí -al igual que en los demás lugares de Bolivia- lo realiza el personal sanitario (médico, enfermera y auxiliar de enfermería) a través de planillas, donde son registrados los motivos de consulta del paciente. El dato estadístico rellenado en las planillas epidemiológicas es depositado en el Servicio Departamental de Salud (SEDES) y de ahí se envía al Ministerio de Salud en donde se elaboran los datos epidemiológicos del país en el Servicio Nacional de Información en Salud (SNIS).

El registro (la planilla a rellenar) es diseñado por el SNIS y el Instituto Nacional de Estadística (INE) que, a su vez, es influenciado o asesorado por los lineamientos de la Organización Panamericana de la Salud (OPS), Organización Mundial de la Salud (OMS) y organismos de cooperación internacional. Desde hace varias décadas la importancia en la recolección del dato estuvo centrada en lo maternoinfantil, debido a que los registros epidemiológicos en países periféricos daban como resultado una alta mortalidad materno-infantil; fue en estos países donde más programas y políticas dirigidas a la mujer y el niño se desarrollaron (a pesar de ello, el caso boliviano no presentó muchos cambios a lo largo del tiempo). El hecho de homogeneizar políticas y programas de salud en América Latina no dio lugar a resultados muy óptimos. El caso boliviano es un buen ejemplo por su diversidad étnica (existen 36 grupos indígenas diferentes), con sus diversas culturas y diferentes concepciones de salud, enfermedad y atención; sin embargo, la diversidad no es tenida en cuenta en el registro del dato. Se parte de un boliviano homogéneo tanto en las tierras altas como en las bajas del país, por lo que se presupone que un indígena moseten es igual a un indígena quechua, a un baure, a un yaminahua, a un ese-ejjas, a un pakahuara, a un siriono, a un canichana, a un cayubaba, a un itonama, a un guaraní, a un mestizo o a un criollo. El hecho de no incorporar la heterogeneidad en las planillas epidemiológicas, concluye en un registro homogeneizador en el que las diferencias no aparecen; y desde el momento en que el registro es homogéneo, los resultados sobre las necesidades en salud en los diferentes departamentos también pasan a ser homogéneos, acercándose por lo tanto poco a la realidad del país (t).

El hecho de no tener en cuenta la diversidad implica, a su vez, no tener en cuenta ciertas categorías. No tan solo la étnica, sino también de género, ya que los hombres prácticamente no aparecen, y no por el hecho de que tengan una esperanza de vida mayor que las mujeres, sino porque los lineamientos políticos están sustentados en los datos epidemiológicos que dan como resultado una alta tasa de mortalidad materno-infantil. El aporte económico internacional se centró en prestar mayor atención a lo materno-infantil (u). Este hecho implicó la creación de planillas específicas para su registro, dejando de lado la realidad epidemiológica que no entraba en estas planillas cerradas. Esta circunstancia generó durante muchos años el hecho de que los datos más importantes que aparecían en los registros estuvieran centrados en las muertes de las mujeres y los niños y que la mayoría de los programas se dirigieran y se dirijan actualmente a ellos.

Otro de los problemas de los registros epidemiológicos es que se realizan exclusivamente sobre la base de los pacientes que llegan a los servicios de salud. Los datos epidemiológicos no son recogidos en las comunidades y barrios sino exclusivamente sobre la base de las personas que recurren a los servicios. Existiendo, por lo tanto, un subregistro de las patologías y causas más importantes de enfermedad y muerte de la población, teniendo en cuenta que en la zona andina de Bolivia (sobre todo en el área rural) muchos centros de salud son escasamente visitados. A ello cabe añadir la existencia de numerosos cementerios clandestinos, donde las muertes no se declaran y por lo tanto, no quedan registradas en ningún lugar.

La poca recurrencia a los servicios de salud por parte de la población andina se debe a la poca capacidad resolutiva que tienen dichos servicios, al maltrato del personal sanitario a la población, a la poca confianza en el servicio de salud por parte de la población y a la falta de una salud pública gratuita (15). Mientras que la existencia de cementerios clandestinos se debe -entre otros factores- a la situación de pobreza. Para poder ser enterrado en el cementerio de la 
ciudad se necesita el certificado de defunción y la compra del lugar para realizar el entierro. Muchos individuos no poseen recursos suficientes para poder realizar el entierro de una forma legal. Otro de los motivos obedece a que no se desea que las muertes sean declaradas, como en el caso de los infanticidios, abortos, suicidios, homicidios, etc.

\section{ALGUNOS ELEMENTOS PARA ENTENDER CÓMO SE REALIZAN LOS REGISTROS}

La población total del municipio de Potosí en el año 2002 era de 145.057 habitantes (10) y el promedio de esperanza de vida al nacer en el departamento de Potosí era de 57 años (55 años en los hombres y 59 en las mujeres) (9). A pesar de conocer el dato de que la esperanza de vida en Potosí era menor en los hombres que en las mujeres, la mayoría de los programas de salud se dirigían a las mujeres.

En la ciudad de Potosí existen 14 centros de Atención Primaria de la Salud. Casi todos estos centros están compuestos por un médico, una enfermera, un auxiliar de enfermería, una trabajadora social, un administrativo (que en la mayoría de los casos se hace cargo de la farmacia del centro), estudiantes de enfermería y medicina; y en algunos centros, un odontólogo y los Responsables Populares de Salud (cuya función es la de ser mediadores entre la comunidad y el centro de salud; son los únicos miembros del equipo de salud que no están remunerados).

A cada centro de atención primaria le corresponde una población que varía entre los 9.000 y los 13.000 habitantes. La consulta al paciente se realiza aproximadamente en unos 15 minutos, empleándose la mayor parte de ese tiempo en el registro de los formularios -elaborados manualmente ya que los centros de salud no están informatizados-, los cuales son enviados al SEDES y al SNIS.

En la consulta, dependiendo de cada profesional, algunos optan por no dedicar mucho tiempo a examinar al paciente, debido a la cantidad de datos que deben ser rellenados; otros profesionales, por el contrario, prefieren atender bien y, por lo tanto, no queda tiempo para rellenar los formularios. En estos casos muchas veces se decide dejar el rellenado del formulario para el final del día o para el comienzo de cada semana. Ello supone que el rellenado se realiza dependiendo de la memoria de cada profesional, y que en ocasiones, cuando los datos no se recuerdan, se inventan, y como en los registros solo aparecen ciertas patologías, éstas son exclusivamente las que se registran.

Cuando el médico no puede definir las causas de muerte de un fallecido, lo más común es que se registre que murió por paro cardio-respiratorio, motivo por el cual aparece como una de las principales causas de muerte en el país y en Potosí.

Durante el tiempo de trabajo en la ciudad, los programas de salud estaban dirigidos (exceptuando el de tuberculosis) a la mujer y el niño. Es decir, el SUMI hacía gratuita la consulta de las mujeres embarazadas y de los niños hasta los cinco años, siendo también gratuitas las consultas dentro del programa de planificación familiar y del de tuberculosis; el resto de las consultas debían ser pagadas. Éste es uno de los motivos por el cual en los centros públicos de atención primaria apenas existen consultas de varones, de manera que también son escasos los registros de las patologías que afectan a los hombres. Cuando algún hombre en la ciudad de Potosí padece algún tipo de patología, habitualmente recurre a médicos privados.

Esta manera de registrar los datos da como resultado las Figura 1 y 2, extraídas de publicaciones oficiales sobre las principales causas de muerte en Bolivia y Potosí. Como podemos ver en las figuras mencionadas, las causas de muerte están agrupadas en grandes grupos, sin dar cabida a la especificidad de las patologías y, como veremos, tampoco a las causas de muerte reales que existen en la ciudad.

El motivo de reproducir los datos tal como fueron publicados oficialmente (Figura $1 \mathrm{y}$ 2), tiene especial importancia, ya que sirven de base para la creación de políticas y programas de salud, tanto a nivel nacional como internacional (cooperaciones internacionales, ONG y agencias de desarrollo que intervienen en el país); a pesar de que se considera que existe un subregistro del $66 \%$ en todo el territorio nacional (16 p.12). Como podemos observar en las Figuras 1 y 2 , no se detaIlan las causas de muerte, "por temor a erróneas interpretaciones, debido a las limitaciones que sufren los datos" (16 p.22). El propio Ministerio de Salud y Deportes reconoce que: 
Figura 1. MORTALIDAD POR GRANDES GRUPOS DE CAUSAS. BOLIVIA, 1995-2001. FACSÍMIL DE LOS DATOS PUBLICADOS OFICIALMENTE EN EL AÑO 2005.

Bolivia: Mortalidad por grandes grupos de causas

FRECUENCIAS ABSOLUTAS

\begin{tabular}{|l|c|c|c|c|c|c|c|}
\hline FRECUENCIAS ABSOLUS \\
\hline Código CIE 10 & 1995 & 1996 & 1997 & 1998 & 1999 & 2000 & 2001 \\
\hline Enf. Infecciosas & 1316 & 1097 & 1151 & 1212 & 1108 & 963 & 849 \\
\hline Tumores & 997 & 953 & 1103 & 1086 & 1127 & 1106 & 1048 \\
\hline Enf. Sangre & 144 & 192 & 180 & 170 & 138 & 134 & 104 \\
\hline Enf. Endócrinas & 582 & 543 & 557 & 581 & 542 & 468 & 414 \\
\hline Enf. Mentales & 202 & 219 & 199 & 176 & 153 & 159 & 149 \\
\hline Enf. S. Nervioso & 224 & 211 & 234 & 221 & 192 & 189 & 165 \\
\hline Enf. O. Sentidos & 2 & 1 & 0 & 1 & 1 & 1 & 0 \\
\hline Enf. S. Circulatorio & 1716 & 1704 & 1832 & 1885 & 1778 & 1607 & 1583 \\
\hline Enf. S. Respiratorio & 1590 & 1354 & 1556 & 1458 & 1336 & 1061 & 1121 \\
\hline Enf. S. Digestivo & 890 & 885 & 980 & 951 & 937 & 901 & 961 \\
\hline Enf. Piel & 7 & 12 & 13 & 11 & 16 & 18 & 13 \\
\hline Enf. Osteo-musculares & 39 & 23 & 25 & 30 & 33 & 28 & 36 \\
\hline Enf. S. Urogenital & 487 & 451 & 497 & 484 & 456 & 417 & 469 \\
\hline Embarazo y Parto & 54 & 48 & 46 & 32 & 40 & 18 & 23 \\
\hline Enf. Perinaiales & 319 & 329 & 328 & 346 & 283 & 239 & 235 \\
\hline Malf. Congenitas & 27 & 33 & 39 & 24 & 33 & 31 & 20 \\
\hline S/S mal Diagnóstico & 13523 & 13110 & 14513 & 14192 & 13641 & 10474 & 9152 \\
\hline Consecuencias C. Ext. & 1286 & 1269 & 1407 & 1456 & 1270 & 1246 & 1209 \\
\hline Causas Externas & 1334 & 1323 & 1505 & 1385 & 1213 & 1112 & 1052 \\
\hline Tot. Causas Exter & 2520 & 2592 & 2912 & 2841 & 2483 & 2358 & 2261 \\
\hline TOTAL & 24739 & 23757 & 26165 & 25701 & 24297 & 20172 & 18603 \\
\hline
\end{tabular}

TASA POR 100.000 HABITANTES

\begin{tabular}{|l|c|c|c|c|c|c|c|c|}
\hline TASA POR 100.000 & HABITANTES \\
\hline Código CIE 10 & 1995 & 1996 & 1997 & 1998 & 1999 & 2000 & 2001 \\
\hline Enf. Infecciosas & 17,8 & 14,5 & 14,8 & 15,2 & 13,6 & 11,6 & 10,2 \\
\hline Tumores & 13,5 & 12,6 & 14,2 & 13,7 & 13,8 & 13,3 & 12,6 \\
\hline Enf. Sangre & 1,9 & 2,5 & 2,3 & 2,1 & 1,7 & 1,6 & 1,2 \\
\hline Enf. Endócrinas & 7,9 & 7,2 & 7,2 & 7,3 & 6,7 & 5,6 & 5,0 \\
\hline Enf. Mentales & 2,7 & 2,9 & 2,6 & 2,2 & 1,9 & 1,9 & 1,8 \\
\hline Enf. S. Nervioso & 3,0 & 2,8 & 3,0 & 2,8 & 2,4 & 2,3 & 2,0 \\
\hline Enf. O. Sentidos & 0,0 & 0,0 & 0,0 & 0,0 & 0,0 & 0,0 & 0,0 \\
\hline Enf. S. Circulatorio & 23,2 & 22,5 & 23,6 & 23,7 & 21,9 & 19,3 & 19,0 \\
\hline Enf. S. Respiratorio & 21,5 & 17,8 & 20,0 & 18,3 & 16,4 & 12,7 & 13,5 \\
\hline Enf. S. Digestivo & 12,0 & 11,7 & 12,6 & 12,0 & 11,5 & 10,8 & 11,5 \\
\hline Enf. Piel & 0,1 & 0,2 & 0,2 & 0,1 & 0,2 & 0,2 & 0,2 \\
\hline Enf. Osteo-musculares & 0,5 & 0,3 & 0,3 & 0,4 & 0,4 & 0,3 & 0,4 \\
\hline Enf. S. Urogenital & 6,6 & 5,9 & 6,4 & 6,1 & 5,6 & 5,0 & 5,6 \\
\hline Embarazo y Parto & 3,0 & 2,6 & 2,4 & 1,6 & 2,0 & 0,9 & 1,1 \\
\hline Enf. Perinatales & & & & & & & \\
\hline Malf. Congenitas & 0,4 & 0,4 & 0,5 & 0,3 & 0,4 & 0,4 & 0.2 \\
\hline S/S mal Diagnóstico & 182,7 & 172,8 & 186,9 & 178,5 & 167,6 & 125,8 & 109,9 \\
\hline Consecuencias C. Ext. & 17,4 & 16,7 & 18,1 & 18,3 & 15,6 & 15,0 & 14,5 \\
\hline Causas Externas & 18,0 & 17,4 & 19,4 & 17,4 & 14,9 & 13,4 & 12,6 \\
\hline Tot. Causas Exter & 35,4 & 34,2 & 37,5 & 35,7 & 30,5 & 28,3 & 27,1 \\
\hline
\end{tabular}

Fuente: Estadisticas de Mortalidad de Bolivia, datos provenientes del Registro Civil 1995 - 2001

$1 \mathrm{ClE}$ 10: Clasificación Internacional de Enfermedades en su décima revisión, Organización Mundial de la Salud.

Las tasas pueden no ser representativas por el subregistro existente.

Fuente: Ministerio de Salud y Deportes (16 p.88)

...esta información pone en evidencia las debilidades de las estadísticas sobre mortalidad derivadas de las actas de defunción de los registros civiles del país. (16 p.4)

Pero a pesar de ello, son los datos epidemiológicos con los que cuentan los organismos de salud tanto nacionales como internacionales.

El método etnográfico utilizado durante el período de un año de trabajo de campo permitió obtener datos que no aparecen en los registros epidemiológicos y entender también el contexto en el que éstos aparecen.

\section{LAS PROBLEMÁTICAS DE SALUD PÚBLICA NO REGISTRADAS EN LOS DATOS EPIDEMIOLÓGICOS}

A pesar de que no se realizó un estudio cuantitativo, la permanencia de un año en la ciudad permitió conocer muertes y accidentes -muy frecuentes- en las minas, no solo en el Cerro Rico, sino también en minas de alrededor. Solo algunas emisoras de radio de la ciudad daban la noticia de los fallecidos o accidentados en las minas. En los periódicos locales y en la televisión no aparecían como noticia. Sin embargo, cuando acontecía un accidente de tránsito (a pesar de que en esos años existían pocas movilidades en la ciudad), éste salía anunciado en primera página de los periódicos. La muerte en las minas dejaba de ser noticia en un lugar donde la frecuencia de muerte era tan común.

Esta causa de muerte no quedaba registrada en los datos epidemiológicos, a pesar de que para la población y el personal sanitario, era considerada como una de las principales causas de fallecimiento entre los hombres de la ciudad. Los accidentes y muertes laborales son registrados por la policía (siempre y cuando sean declarados). La disociación que existe entre los registros de la policía, servicios sociales y cementerios, y los 
Figura 2. MORTALIDAD POR GRANDES GRUPOS DE CAUSAS. POTOSÍ, 1995-2001. FACSÍMIL DE LOS DATOS PUBLICADOS OFICIALMENTE EN EL AÑO 2005.

Potosí: Mortalidad por grandes grupos de causas

FRECUENCIAS ABSOLUTAS

\begin{tabular}{|l|c|c|c|c|c|c|c|}
\hline Código CIE 10 & 1995 & 1996 & 1997 & 1998 & 1999 & 2000 & 2001 \\
\hline Enf. Infecciosas & 123 & 96 & 94 & 109 & 87 & 90 & 59 \\
\hline Tumores & 54 & 45 & 59 & 45 & 67 & 66 & 44 \\
\hline Enf. Sangre & 12 & 12 & 13 & 10 & 12 & 13 & 9 \\
\hline Enf. Endócrinas & 50 & 55 & 67 & 60 & 51 & 40 & 28 \\
\hline Enf. Mentales & 25 & 36 & 37 & 28 & 27 & 20 & 10 \\
\hline Enf. S. Nervioso & 19 & 27 & 25 & 20 & 14 & 11 & 11 \\
\hline Enf. O. Sentidos & 0 & 0 & 0 & 0 & 0 & 0 & 0 \\
\hline Enf. S. Circulatorio & 118 & 155 & 173 & 157 & 124 & 125 & 80 \\
\hline Enf. S. Respiratorio & 152 & 149 & 138 & 147 & 148 & 119 & 77 \\
\hline Enf. S. Digestivo & 68 & 69 & 77 & 80 & 60 & 57 & 38 \\
\hline Enf. Piel & 0 & 1 & 0 & 0 & 0 & 1 & 0 \\
\hline Enf. Osteo-musculares & 1 & 0 & 3 & 2 & 1 & 3 & 1 \\
\hline Enf. S. Urogenital & 40 & 48 & 64 & 42 & 27 & 22 & 20 \\
\hline Embarazo y Parto & 5 & 3 & 2 & 2 & 2 & 1 & 1 \\
\hline Enf. Perinatales & 49 & 51 & 50 & 51 & 45 & 37 & 14 \\
\hline Malf. Congenitas & 5 & 3 & 0 & 2 & 0 & 3 & 1 \\
\hline S/S mal Diagnóstico & 2008 & 1945 & 2364 & 1902 & 1723 & 1156 & 1001 \\
\hline Consecuencias C. Ext. & 118 & 107 & 110 & 151 & 150 & 101 & 86 \\
\hline Causas Externas & 235 & 261 & 287 & 227 & 203 & 132 & 123 \\
\hline Tot. Causas Exter & 353 & 368 & 397 & 378 & 353 & 233 & 209 \\
\hline TOTAL & 3082 & 3063 & 3563 & 3035 & 2741 & 1997 & 1603 \\
\hline
\end{tabular}

TASA POR 100.000 HABITANTES

\begin{tabular}{|l|c|c|c|c|c|c|c|}
\hline TASA POR & 100,000 \\
\hline Código CIE 10 & 1995 & 1996 & 1997 & 1998 & 1999 & $\mathbf{2 0 0 0}$ & $\mathbf{2 0 0 1}$ \\
\hline Enf. Infecciosas & 16,9 & 13,0 & 12,6 & 14,4 & 11,4 & 11,6 & 7,6 \\
\hline Tumores & 7,4 & 6,1 & 7,9 & 6,0 & 8,8 & 8,5 & 5,7 \\
\hline Enf. Sangre & 1,6 & 1,6 & 1,7 & 1,3 & 1,6 & 1,7 & 1,2 \\
\hline Enf. Endócrinas & 6,9 & 7,5 & 9,0 & 7,9 & 6,7 & 5,2 & 3,6 \\
\hline Enf. Mentales & 3,4 & 4,9 & 5,0 & 3,7 & 3,5 & 2,6 & 1,3 \\
\hline Enf. S. Nervioso & 2,6 & 3,7 & 3,3 & 2,6 & 1,8 & 1,4 & 1,4 \\
\hline Enf. O. Sentidos & 0,0 & 0,0 & 0,0 & 0,0 & 0,0 & 0,0 & 0,0 \\
\hline Enf. S. Circulatorio & 16,2 & 21,0 & 23,2 & 20,8 & 16,2 & 16,1 & 10,3 \\
\hline Enf. S. Respiratorio & 20,9 & 20,2 & 18,5 & 19,4 & 19,3 & 15,4 & 9,9 \\
\hline Enf. S. Digestivo & 9,3 & 9,4 & 10,3 & 10,6 & 7,8 & 7,4 & 4,9 \\
\hline Enf. Piel & 0,0 & 01 & 0,0 & 0,0 & 0,0 & 0,1 & 0,0 \\
\hline Enf. Osteo-musculares & 0,1 & 0,0 & 0,4 & 0,3 & 0,1 & 0,4 & 0,1 \\
\hline Enf. S. Urogenital & 5,5 & 6,5 & 8,6 & 5,6 & 3,5 & 2,8 & 2,6 \\
\hline Embarazo y Parto & 3,0 & 1,8 & 1,2 & 1,2 & 1,2 & 0,6 & 0,6 \\
\hline Enf. Perinatales & & & & & & & \\
\hline Malf. Congenitas & 0,7 & 0,4 & 0,0 & 0,3 & 0,0 & 0,4 & 0,1 \\
\hline S/S mal Diagnóstico & 275,8 & 263,7 & 316,6 & 251,6 & 225,1 & 149,2 & 129,2 \\
\hline Consecuencias C. Ext. & 16,2 & 14,5 & 14,7 & 20,0 & 19,6 & 13,0 & 11,1 \\
\hline Causas Externas & 32,3 & 35,4 & 38,4 & 30,0 & 26,5 & 17,0 & 15,9 \\
\hline Tot. Causas Exter & 48,5 & 49,9 & 53,2 & 50,0 & 46,1 & 30,1 & 27,0 \\
\hline
\end{tabular}

Fuente: Estadisticas de Mortalidad de Bolivia, datos provenientes del Registro Civil 1995 - 2001

1 CIE 10: Clasificación Internacional de Enfermedades en su décima revisión, Organización Mundial de la Salud

Las tasas pueden no ser representativas por el subregistro existente. registros que realiza Salud Pública es uno de los problemas. Los accidentes laborales provocan una mortalidad prematura en los hombres y una esperanza de vida menor que la de las mujeres.

Otra problemática que surgió en la investigación fue el suicidio en adolescentes. Durante el trabajo de campo se suicidó Pedro, hijo de una informante. A partir del funeral, se comenzó a indagar sobre los suicidios, encontrando que el suicidio en adolescentes era algo común: se suicidaban con raticidas o se ahorcaban (v). Estas muertes tampoco quedaban registradas en los datos epidemiológicos porque en los formularios no existe la casilla "suicidio". No está contemplado en los datos de salud pública de Bolivia (como se puede observar en las Figuras 1 y 2), siendo considerado un problema exclusivamente judicial (w).

Hasta hace no muchos años los sacerdotes católicos no celebraban la misa de difunto a una persona que se suicidaba. Ésta es la razón por la cual muchas veces las familias ocultaban la causa de muerte, a fin de poder recibir la bendición del sacerdote para que el alma no quedase vagando (en la creencia local, se considera que un muerto sin la misa y la bendición del sacerdote no descansará).

Se analizaron las condiciones en las que ocurrían estos hechos. Una de las mayores problemáticas de Potosí es el alcoholismo, que afectaba al número de suicidios, accidentes de todo tipo, homicidios, violencia doméstica, embarazos no deseados en adolescentes y violaciones intrafamiliares.

En las áreas mineras de la zona andina es sabido que todos los viernes se debe de ch'allar al Tío (x), es decir, se bebe alcohol, que junto con el tabaco y las hojas de coca, son considerados elementos de este mundo para conectar con los dioses, encontrar mineral y ser protegido de los accidentes en el interior de la mina. Esta práctica 
relacionada con el trabajo minero es asociada desde la salud pública a prácticas culturales que no pueden ser modificadas porque forman parte de la cultura, de tal manera que no se considera un problema importante para ser registrado en los formularios de morbimortalidad.

Para Absi (17) (una antropóloga que realizó una investigación sobre el trabajo en las minas), el alcohol es una de las principales causas de muerte entre los mineros.

Un hecho es la ch'alla de los viernes que practican los mineros y el consumo de alcohol en ceremonias rituales (ofrendas a la Pachamama, bodas, entierros, etc.) dentro de la cultura quechua; y otro hecho es el consumo de alcohol en adolescentes (en Potosí es muy común encontrar adolescentes ebrios en la calle), que no está asociado a aspectos culturales, sino socioeconómicos. A pesar de ello, no existe la posibilidad de que el personal de salud inscriba como causa de muerte o enfermedad el alcoholismo, porque en los formularios a rellenar esta patología no aparece, no obstante ser considerada una de las principales causas de muerte en la ciudad, reconocida por la población y por todos los sistemas médicos de atención a la salud.

En la población infantil, una de las principales causas de muerte que aparecen en los datos epidemiológicos es la desnutrición, y si bien este dato es real, se pudo observar cómo esta patología también se encuentra como causa de muerte en los ancianos, hecho que tampoco queda registrado. Parte de la situación de extrema pobreza de muchos hogares potosinos obedece al hecho de tener que elegir entre alimentar a los hijos o a los ancianos, eligiendo comúnmente alimentar a los niños. Los ancianos no aparecen en los registros con problemáticas específicas.

Durante el trabajo de campo se pudo presenciar cómo se realizaba uno de los registros referidos a la problemática materno-infantil. El personal de salud realizaba una encuesta en las casas donde había habido algún parto reciente. El cuestionario era sobre cómo había sido el embarazo, cuándo, dónde, y si la mujer o su bebé habían sufrido complicaciones. El registro se realizaba en las casas de las que se tenía noticia por haber tenido alguna wawa (término utilizado para denominar a los niños y bebés) en los últimos meses.
Llegábamos a las casas, la enfermera tocaba a la puerta y preguntaba por la señora $X$; y en la puerta de la casa, parados, se rellenaba un formulario en aproximadamente tres minutos.

Destacaremos una parte del diálogo para poder explicar cómo en la recolección de los datos cuantitativos, no se tiene en cuenta el cómo ha sido efectuado este proceso (elemento importantísimo dentro de la metodología cualitativa), no proporcionando información fiable, aunque se tengan cifras al respecto.

Enfermera: Buenos días, estamos pasando por las casas haciendo algunas preguntas... somos del centro de salud $X$. ¿Ha tenido una wawa recientemente?

Mujer: Sí.

Enfermera: ¿Usted ha tenido algún problema en

el embarazo?

Mujer: No.

Enfermera: ¿Ha tenido algún aborto?

Mujer: No.

Enfermera: ¿Nunca ha tenido complicaciones...

o... ha abortado?

Mujer: No.

Enfermera: ¿A su niño le está poniendo las vacunas? ¿Lo está llevando al centro de salud?

Mujer: Sí.

Enfermera: Bueno, no se olvide de llevar los niños al centro. Gracias, que tenga un buen día.

Estas respuestas de las mujeres se reiteraban constantemente en las encuestas hechas por el personal sanitario. Todas contestaban no haber tenido nunca un aborto. La manera en que se realizaban las preguntas incidían en que se registrasen datos que no se correspondían con la realidad, no tan solo por la manera de preguntar sino por cómo se preguntaba y en función del tiempo dedicado a recoger la información. Obtener información real a través de una encuesta sobre una temática tan compleja, si ésta no se hace dentro del contexto de una metodología cualitativa, hace que sea casi imposible obtener información fidedigna. Es como si se preguntase: "¿Usted ha matado a alguien?", sabiendo que el asesino no solo está penado por la ley sino que es un sujeto social rechazado por la sociedad en la que vive. La respuesta en una encuesta cerrada siempre será "no" (y). 
La permanencia en el interior de las casas y la confianza establecida con las mujeres, permitía obtener datos diferentes de los que registraba el equipo de salud. Conocer a médicos que practicaban el aborto en la ciudad y conocer las numerosas prácticas tradicionales que las mujeres llevaban a cabo para interrumpir el embarazo, permitía conocer estos datos no registrados, entender el porqué de estas prácticas y los motivos por los cuales eran ocultadas. Y uno de estos motivos es sin duda, la ilegalidad del aborto en el país, pero también la ilegalidad dentro de la cultura quechua, ya que se considera que esta práctica atrae males, padecimientos y enfermedades a la comunidad.

Poco a poco se pudo observar la violencia doméstica en los hogares y obtener información sobre la violación de padrastros a hijastras, oculta ante las autoridades y los servicios sociales. Era algo tan habitual en los sectores populares de la ciudad que todo el mundo hablaba de ello con cierta normalidad. Al tomar conocimiento del primer caso se comenzó a indagar y fue sorprendente el número elevadísimo de mujeres que habían sufrido esta agresión. En las casas potosinas existe un gran hacinamiento y es frecuente que en la misma cama duerman padres e hijos. Si se suma al alto índice de alcoholismo y al hecho de que es común encontrar hombres y mujeres con segundas o terceras parejas, no es de extrañar la frecuencia de padrastros en las casas.

El método etnográfico permitió ir recogiendo información que el personal sanitario conocía pero que no quedaba registrado en los datos epidemiológicos. O información que no manejaban y que, si conocían, era considerada parte de las problemáticas sociales y no de las sanitarias.

Es importante saber que el personal sanitario maneja información valiosa sobre causas de enfermedad y muerte que no es tenida en cuenta por el SEDES, el SNIS y el INE, organismos que se manejan exclusivamente en base a categorías cerradas y cuyos datos son registrados casi exclusivamente en los servicios de salud. Pero para conocer las problemáticas reales no solo es necesario tener en cuenta el conocimiento del personal sanitario sino también el que tiene la población y los representantes de los demás sistemas de atención a la salud que se encuentran en un lugar determinado.

\section{EL MÉTODO ETNOGRÁFICO EN LA RECOLECCIÓN DE INFORMACIÓN DE TODOS LOS SISTEMAS MÉDICOS}

Identificar a todos los representantes de los sistemas médicos de atención a la salud implica reconocerlos como los sujetos sociales con mayor conocimiento sobre la salud, poseedores de un saber importante para la recolección del dato epidemiológico (z). Los sistemas médicos que se encuentran en la ciudad de Potosí, como ya hemos visto, son el sistema biomédico, el sistema médico tradicional, el sistema médico religioso (a través de la iglesia evangélica) y el sistema más importante: el de autoatención (8).

Cada uno de estos sistemas reconoce diferentes causas de muerte, por ello la importancia de tenerlos en cuenta, ya que todas las enfermedades, padecimientos y muertes pasan por alguno o varios de estos sistemas. Si el registro del dato se realiza exclusivamente en el sistema biomédico, obtendríamos un subregistro y poco acercamiento a la realidad, tal y como podemos ver en los datos epidemiológicos actuales.

Según el personal sanitario, las causas que aparecían con más frecuencia en los centros de atención primaria de Potosí eran los problemas de desnutrición, seguidos de las infecciones respiratorias agudas (IRAS) y enfermedades diarreicas agudas (EDAS), enfermedades de transmisión sexual, casos de tuberculosis, sarna, varicela y alergias. Aunque muchas de las causas de atención en el centro eran los controles de embarazos y niños.

El personal de salud de los centros de atención primaria consideraba que la principal causa de muerte en la ciudad de Potosí eran los accidentes laborales asociados al trabajo en las minas (a pesar de no ser declarados como tales). Otras causas eran la tuberculosis, silicosis, alcoholismo, junto con las complicaciones en el parto.

Según el personal sanitario, las principales causas de muerte en los niños eran las diarreas, los accidentes, desnutrición (provocada por diarrea), neumonía y deshidratación, mientras que, en el caso de los adolescentes, aparecían los suicidios y los accidentes como causas principales. Por otra parte, la violencia doméstica, el alcoholismo y los problemas de higiene aparecían como las problemáticas de salud pública que el personal de 
CUadro 1. PRINCIPALES CAUSAS DE MUERTE SEGÚN EL PERSONAL SANITARIO DE LOS CENTROS DE ATENCIÓN PRIMARIA. CIUDAD DE POTOSÍ, BOLIVIA. 2004.

\begin{tabular}{lll}
\hline MORTALIDAD INFANTIL & MORTALIDAD HOMBRES & MORTALIDAD MUJERES \\
\hline IRASa & Accidentes laborales & Complicaciones de embarazo \\
EDAS & Silicosis & Accidentes \\
Neumonía & Tuberculosis & Cáncer \\
Desnutrición & Alcoholismo & \\
Accidentes & Problemas cardio-respiratorios &
\end{tabular}

Fuente: Elaboración propia.

a Infecciones respiratorias agudas.

b Enfermedades diarreicas agudas

salud de los centros de atención primaria consideraba como las más importantes de la ciudad, aún cuando no aparecían en los datos oficiales.

\section{LAS MUERTES EN POTOSÍ SEGÚN EL PERSONAL SANITARIO}

Según las referencias del personal sanitario (Cuadro 1), existen mayores muertes en el segmento de la población masculina, presentando como mayor frecuencia las muertes por accidentes laborales relacionadas con el trabajo en las minas, seguidas de las producidas por silicosis, alcoholismo y tuberculosis, mientras que en el segmento de población femenina la primera causa de muerte siguen siendo las complicaciones en el parto y puerperio -aunque se considera que en un porcentaje mucho menor que en la zona rural-, accidentes y cáncer. La mortalidad infantil es elevada en la ciudad, y las causas principales son las IRAS y las EDAS, seguidas de neumonía, desnutrición y accidentes (8).

\section{LAS MUERTES SEGÚN LOS TERAPEUTAS TRADICIONALES}

Para los terapeutas tradicionales (Cuadro 2), las causas de muerte más frecuentes resultan similares a las que señalan los datos recogidos por las madres: accidentes, mal de mina, gloria, qayqasqa (aa), parto, embrujo y susto. La diferencia entre las causas de muerte de la población masculina y la femenina se encuentra en los accidentes laborales en el caso de los

Cuadro 2. PRINCIPALES CAUSAS DE MUERTE SEGÚN LOS TERAPEUTAS TRADICIONALES DE POTOSÍ, BOLIVIA. 2004.

\begin{tabular}{lll}
\hline MORTALIDAD INFANTIL & MORTALIDAD HOMBRES & MORTALIDAD MUJERES \\
\hline \multirow{2}{*}{ Susto a } & & \\
Embrujoa & Accidentes laborales & Parto \\
Gloria a & Embrujo & Gloria \\
Enfermedades respiratorias & Susto & Embrujo \\
& Qayqasqa $a$ & Susto \\
& Alcoholismo & Qayqasqa \\
& & Alcoholismo
\end{tabular}

Fuente: Elaboración propia.

a patología popular. 
Cuadro 3. PRINCIPALES CAUSAS DE MUERTE SEGÚN LOS PASTORES EVANGÉLICOS DE LA CIUDAD DE POTOSÍ, BOLIVIA. 2004.

\begin{tabular}{lll}
\hline MORTALIDAD INFANTIL & MORTALIDAD HOMBRES & MORTALIDAD MUJERES \\
\hline Diarrea & Accidentes laborales & \\
Desnutrición & Mal de mina a & Cáncer de mama \\
& Alcoholismo & Cáncer de matriz \\
& Brujería & Brujería \\
& Suicidio (adolescentes)
\end{tabular}

Fuente: Elaboración propia.

a Nombre local que se da a la silicosis.

b patología popular.

hombres y en el parto en el de las mujeres, apareciendo como la causa de muerte infantil más importante el susto. En cuanto a la patología del embrujo en la población infantil, hay que decir que si bien el embrujo se dirige a los padres, es común que afecte a otros miembros de la familia, normalmente a los más frágiles, a los integrantes de la población infantil (8).

Según estos informantes, la mayoría de causas de muerte entre la población son patologías populares, siendo la más común en los hombres la de los accidentes en la mina y, en las mujeres, las complicaciones en el parto. Para ambos sexos los terapeutas tradicionales reconocen como causa de muerte el alcoholismo, sobre la que consideran aumenta cada vez más. Reconocen mayor esperanza de vida en las mujeres y un mayor número de causas de muerte en los varones.

\section{LAS MUERTES SEGÚN LOS PASTORES EVANGÉLICOS}

Desde la visión de los pastores evangélicos, (Cuadro 3) las causas más frecuentes de muerte en la población infantil de Potosí son la diarrea y la desnutrición, mientras que para los hombres vuelven a aparecer, al igual que en los representantes de los otros sistemas médicos, los accidentes asociados al trabajo en las minas, el mal de mina, el alcoholismo, apareciendo también la brujería como causa de muerte. Entre los adolescentes se considera que las muertes más frecuentes son los suicidios, mientras que entre las mujeres el cáncer y la brujería (8).

\section{LAS MUERTES SEGÚN LAS MADRES}

En el Cuadro 4 se pueden observar las principales causas de muerte infantil y de adultos según las madres (8).

En cuanto a los factores por sexo, podemos ver que las causas están asociadas al tipo de trabajo que realiza cada sexo (trabajo en las minas: mal de mina, tuberculosis, accidentes, alcoholismo y en las mujeres por lavar ropa y aborto). Con respecto a los trabajos laborales de las mujeres, la mayoría trabajan lavando ropa, de empleadas domésticas, como pequeñas vendedoras en la calle o en el programa Plan Nacional de Empleo (PLANE). Como se pudo comprobar, el trabajo que realizan las mujeres en el PLANE es un trabajo de construcción, para el que necesitan levantar piedras muy pesadas. La mayoría de las mujeres que trabajan en este programa llevan a sus hijos a la espalda y, entre las mujeres embarazadas, se producen abortos debido al esfuerzo físico que realizan.

Las mujeres lavanderas lavan la ropa, en la mayoría de los casos, con agua fría, debido a las bajas temperaturas que, sobre todo en los meses de invierno, tiene la ciudad de Potosí. Esta actividad contribuye a que se produzca lo que las madres Ilaman "la muerte por lavar ropa":

\footnotetext{
"Te comienza un dolor en la espalda del frío, de estar todo el día con las manos en agua fría y ese dolor te va dando y te va dando y te enfermas y te mueres."
} 
Cuadro 4. PRINCIPALES CAUSAS DE MUERTE SEGÚN LAS MADRES DE LA CIUDAD DE POTOSÍ, BOLIVIA. 2004.

\begin{tabular}{lll}
\hline MORTALIDAD INFANTIL & MORTALIDAD HOMBRES & MORTALIDAD MUJERES \\
\hline Sustoa & Mal de minab & \\
De recién nacidos & Tuberculosis & Por parto \\
Neumonía & Accidentes en la mina & Sobreparto a \\
Estómago vacioa & Alcoholismo & Aborto \\
Orejoa & Accidentes & Por lavar ropa a \\
Accidentes & Embrujoa & Del corazón \\
Fría & Arrebatoa & Embrujo \\
Desnutrición & Gloria a & Cáncer \\
& & Arrebato
\end{tabular}

Fuente: Elaboración propia.

a Patología popular.

b Nombre local que se da a la silicosis.

\section{LA MUERTE SEGÚN LOS DISTINTOS REPRESENTANTES DE LOS SISTEMAS MÉDICOS}

En el Cuadro 5 se puede observar cómo el personal sanitario (bb) solo reconoce las patologías biomédicas, mientras que las madres, al igual que los terapeutas tradicionales y los pastores evangélicos, reconocen tanto las patologías populares como las biomédicas en las principales causas de muerte de la ciudad de Potosí.

Como podemos ver en el Cuadro 5, los accidentes laborales, las enfermedades relacionadas fundamentalmente con las minas -la silicosis, la tuberculosis y el alcoholismo- eran las patologías que reconocían todos los sistemas médicos (biomédico, tradicional, religioso y de autoatención). Sin embargo, exceptuando la tuberculosis, ninguna de ellas aparecía en los datos epidemiológicos. Las patologías populares (susto, qayqasqa, orejeadura, frío, estómago vacío, gloria, sobreparto y embrujo) no son reconocidas por el saber biomédico, pero sí por los otros sistemas, siendo el sistema de autoatención el que más causas de muertes encuentra en la ciudad de Potosí.

Entre las causas de muerte reconocidas por todos los sistemas médicos, destacan las relacionadas con el trabajo masculino y femenino. Este dato no aparece reflejado en los índices epidemiológicos a nivel nacional ni departamental.
Consecuentemente, no existen políticas sanitarias que incidan en un mejoramiento de las condiciones de trabajo o en políticas destinadas a la prevención de accidentes laborales.

Al mismo tiempo, observamos que los representantes de todos los sistemas médicos menos el biomédico reconocen como causas de muerte en la ciudad de Potosí no solo patologías biomédicas, sino también patologías populares como pueden ser el susto y la brujería.

De todo lo recorrido hasta aquí, se desprende que las problemáticas más relevantes en la ciudad de Potosí, no tan solo por su nivel de incidencia en la salud individual sino asociadas a otros aspectos de la vida cotidiana, son el alcoholismo, seguido del suicidio en adolescentes, la desnutrición en ancianos y el embarazo no deseado en adolescentes. Sin embargo, estas problemáticas no son consideradas como prioritarias ni en la ciudad ni en el departamento de Potosí, y no existen programas especiales que puedan ayudar a paliar tales problemas. Estas problemáticas no hubieran aparecido si se hubiera realizado una encuesta entre la población o entre todos los sistemas de salud. Esta información pudo obtenerse a partir del método etnográfico, y no solo por lo que los sujetos sociales dicen sino porque se observaron sus prácticas. 
Cuadro 5. PRINCIPALES CAUSAS DE MUERTE SEGÚN LOS DISTINTOS REPRESENTANTES DE LOS SISTEMAS MÉDICOS DE LA CIUDAD DE POTOSÍ, BOLIVIA. 2004.

\begin{tabular}{|c|c|c|c|c|}
\hline & $\begin{array}{c}\text { SISTEMA } \\
\text { BIOMÉDICO }\end{array}$ & $\begin{array}{l}\text { SISTEMA MÉDICO } \\
\text { TRADICIONAL }\end{array}$ & $\begin{array}{l}\text { SISTEMA MÉDICO } \\
\text { RELIGIOSO }\end{array}$ & $\begin{array}{l}\text { SISTEMA DE } \\
\text { AUTOATENCIÓN }\end{array}$ \\
\hline & Personal sanitario & Terapeutas tradicionales & Pastores evangélicos & Madres \\
\hline Accidentes en la mina & $x$ & $x$ & $x$ & $x$ \\
\hline Mal de mina ${ }^{a}$ & $\mathrm{x}$ & $\mathrm{x}$ & $\mathrm{x}$ & $x$ \\
\hline Tuberculosis & $x$ & $\mathrm{x}$ & & $x$ \\
\hline Alcoholismo & $\mathrm{x}$ & $\mathrm{x}$ & $\mathrm{x}$ & $x$ \\
\hline Por lavar la ropab & & & & $x$ \\
\hline Embrujob & & $x$ & $x$ & $x$ \\
\hline Parto & $\mathrm{x}$ & $\mathrm{x}$ & & $\mathrm{x}$ \\
\hline Sobrepartob & & $x$ & & $x$ \\
\hline Gloriab $^{b}$ & & $x$ & & $x$ \\
\hline Aborto & & & & $\mathrm{x}$ \\
\hline Neumonía & $\mathrm{x}$ & & & $\mathrm{x}$ \\
\hline Estómago vacíob & & & & $x$ \\
\hline Fríob & & & & $x$ \\
\hline Orejeadura/orejob & & $x$ & & $x$ \\
\hline Del corazón & & & & $\mathrm{x}$ \\
\hline Diarrea & & & $\mathrm{x}$ & $\mathrm{x}$ \\
\hline Enfermedades respiratorias & & $x$ & & \\
\hline Accidentes & $\mathrm{x}$ & $x$ & $\mathrm{x}$ & $x$ \\
\hline Suicidio & & & $\mathrm{x}$ & \\
\hline Enfermedades diarreicas agudas & $\mathrm{X}$ & & $\mathrm{x}$ & \\
\hline Infecciones respiratorias agudas & $x$ & & & \\
\hline Qayqasqab & & $x$ & & \\
\hline Arrebatob & & & & $x$ \\
\hline Desnutrición & $x$ & & $x$ & $x$ \\
\hline Cáncer & $\mathrm{x}$ & & $\mathrm{x}$ & \\
\hline Sustob & & $\mathrm{x}$ & & $x$ \\
\hline
\end{tabular}

Fuente: Elaboración propia.

a Nombre local que se da a la silicosis.

b Patología popular.

Las principales causas de muerte -tanto a nivel nacional, departamental como del municipio de Potosí- son, según los datos oficiales, las materno-infantiles, presentándose como las causas de muerte más frecuentes las enfermedades cardio-respiratorias y las infecciones intestinales. Los datos epidemiológicos ofrecen tan solo una información parcial sobre el problema de la morbimortalidad en Bolivia. Los datos sobre suicidio, homicidio, accidentes, violencia doméstica o alcoholismo entre otros, son registrados por la policía y no forman parte de los registros epidemiológicos del departamento. Es necesario que estas causas epidemiológicas y de salud pública 
sean incorporadas a los registros epidemiológicos para poder generar políticas oportunas de acuerdo con la realidad local.

\section{A MODO DE CONCLUSIÓN}

Como hemos podido ver, no es fácil detectar ciertas patologías y problemáticas de salud pública. Por ello se debe partir de diagnósticos de salud realizados a través del método etnográfico, para que los programas y las políticas sanitarias sean acordes con la realidad.

Pero si la permanencia en campo hubiese sido de cuatro meses (como estaba diseñado en el proyecto inicial), no se hubiese obtenido ni la mitad de la información que se obtuvo tras un año de trabajo de campo permanente.

El método etnográfico permitió conocer ciertas problemáticas de salud pública que no estaban registradas en los datos epidemiológicos, pero también permitió conocer porqué suceden y el contexto en el cual aparecen. La mayoría de los programas de salud en Potosí estaban centrados en la mujer y el niño, pero esta investigación demostró que las causas de muerte y los mayores problemas de salud pública de la ciudad estaban en los hombres y en los adolescentes. Si no se modifican las planillas para el registro del dato, el ámbito de lo materno-infantil siempre figurará como preponderante y todos los programas sanitarios irán dirigidos al mismo tipo de población.

Podemos concluir que para conocer las causas reales de morbimortalidad se han de conocer no tan solo las causas de muerte reconocidas por el sistema biomédico sino las reconocidas por todos los sistemas a los que recurre la población, a fin de poder registrar no únicamente las patologías reconocidas por la medicina institucional sino también las populares reconocidas por la población, diferentes en cada cultura y sociedad.

El susto, por ejemplo, está considerado la primera causa de muerte infantil por la población de Potosí, siendo uno de sus primeros síntomas la diarrea. Y la diarrea es, a su vez, la primera causa de muerte infantil reconocida por los servicios de salud en la ciudad. Sin embargo, las causas del susto y la diarrea, la forma de tratamiento de estas dos patologías y el significado dado a ellas es totalmente diferente. En la cultura quechua, si se quiere implementar un programa de salud para disminuir la mortalidad infantil, se han de conocer estos elementos, además de los aspectos externos: contaminación de las aguas, ambiental, de alimentos, etc.

Son varios los aspectos que deben tenerse en cuenta para que los programas y las políticas de salud no se sustenten sobre datos mal construidos y para que tengan una cierta capacidad de incidencia en la población. Se debería reconocer la existencia de las patologías populares reconocidas por cada cultura para que puedan aparecer en los registros epidemiológicos, ya que la población las reconoce como causas de enfermedad y muerte.

Los datos numéricos para el registro estadístico deberían recogerse dentro de una metodología cualitativa con la utilización del método etnográfico para que los datos sean realmente fiables y representen la realidad. Rescatando el conocimiento de las causas de enfermedad y muerte de los saberes que poseen los representantes de las diversas formas de atención a la salud. De todo lo expuesto hasta aquí se desprende la necesidad de realizar diagnósticos antropológicos que puedan dar cuenta de las problemáticas de una determinada población, previo al diseño de programas y políticas sanitarias.

\section{AGRADECIMIENTOS}

Quiero agradecer a Oriol Romaní por sus aportes a este artículo, que sin duda ayudaron a enriquecerlo y a Constanza Forteza por el tiempo dedicado a la revisión del texto. 


\section{NOTAS FINALES}

a. Esto ya ha sido mostrado por varios autores como el caso de la investigación que realizó Scheper-Hughes (1) en el nordeste del Brasil.

b. La población conoce las causas de muerte y enfermedad, muchas veces, con mayor exactitud de la que suponen los expertos, ya que la población reconoce -comúnmente- los diferentes sistemas médicos y con ellos tanto las patologías biomédicas como las populares.

c. Este aspecto es difícil de encontrar debido a que el sector salud y las cooperaciones internacionales financian diagnósticos que no suelen pasar de los tres meses, mientras que en muchas ocasiones se limitan a 15 días o a un mes.

d. Lo que la población dice hacer es lo que queda registrado en las encuestas y formularios en las que se basan los servicios departamentales de salud y comúnmente las cooperaciones internacionales.

e. Por trabajadores de salud entendemos todos los sujetos sociales que trabajan dentro de los servicios de salud: portero, trabajador manual, médico, enfermero, trabajador social, etc.

f. En Potosí, para el año 2005, la tasa de analfabetismo fue de $21,76 \%$ en los hombres y de $53,3 \%$ en las mujeres del área rural, y de 3,17\% en los hombres y $16,42 \%$ en las mujeres del área urbana (9), hecho que repercute en que muchas personas no reparen en que los productos han caducado, incluidos los medicamentos en las farmacias y en los servicios de salud.

g. Se realizó una entrevista grupal en cada uno de los 14 centros de atención primaria de la ciudad y 3 centros rurales pertenecientes a la ciudad. En cada entrevista estaban presentes todos los profesionales que trabajaban en cada centro de salud: médico, trabajadora social, enfermero, auxiliar de enfermería y en algunos casos odontólogo.

h. Para obtener calidad en la información, la técnica de grupo focal debe ser realizada cuando existe confianza y conocimiento de los sujetos sociales con los que se desea trabajar, es decir, dentro del método etnográfico. Uno de los mayores problemas es la utilización de esta técnica, porque se supone que es la que puede aportar mayor información en menos tiempo, pero si lo que el investigador busca es calidad en el material recogido, esta técnica por sí sola no proporciona información fiable. i. El hecho de observar con mayor profundidad un barrio, no significa restringirse exclusivamente a ese barrio, debido a que las relaciones familiares y extrafamiliares se realizan en distintas zonas de la ciudad.

j. La religión andina está sumamente vinculada con la medicina tradicional e involucra entre otros aspectos la creencia en elementos de la naturaleza (las montañas, la Pachamama, el rayo, etc.) que pueden proteger o enfermar. Esta religión aparece en muchas ocasiones y para muchos sujetos sociales mezclada y sintetizada con la religión católica, pero también encontramos sujetos sociales que usan en la práctica elementos católicos marginales, en donde podemos ver cómo la influencia de la religión católica es mínima y resignificada. La forma en que se distinguieron los informantes de diversas religiones, fue no solo por cómo se autoadscriben sino también por las prácticas religiosas que llevaban a cabo.

k. Por entrevista entendemos a toda aquella información obtenida a través de entrevistas realizadas -con grabador o sin él- pero en las cuales hay una intencionalidad en la recolección del material. Se diferencia de lo que llamaremos información informal, referida a todos aquellos datos recogidos en charlas informales, en donde no existe la intencionalidad de las preguntas. La información informal resultó ser la mejor herramienta utilizada en esta etnografía. El número de entrevistas realizadas a lo largo de todo el trabajo de campo fueron treinta y siete y las entrevistas individuales se realizaron a partir del cuarto mes de permanencia en la ciudad, cuando la relación con los informantes que se habían seleccionado comenzaba a ser fluida .

I. Debido a que los procesos de salud/enfermedad/atención son permanentes en la ciudad, se pudo presenciar numerosos itinerarios terapéuticos (que no fueron contabilizados). Es raro entrar en una vivienda potosina y no encontrar que algún miembro padece alguna enfermedad o padecimiento.

m. Por sistema de autoatención "nos referimos a las representaciones y prácticas que la población utiliza a nivel de sujeto y grupo social para diagnosticar, explicar, atender, controlar, aliviar, aguantar, curar, solucionar o prevenir los procesos que afectan su salud en términos reales o imaginarios, sin la intervención directa e intencional de curadores profesionales, aun cuando estos pueden ser la referencia de la actividad de autoatención" (14 p.14). Por sistema médico-religioso, en la ciudad de Potosí, nos referimos a la Iglesia Evangélica Pentecostal, por tratarse de una forma nueva de tratamiento de la enfermedad por 
parte de la población quechua de la ciudad. Al igual que en el caso de otras formas de atención como pueden ser la tradicional o la biomédica, este sistema posee toda una serie de conocimientos que se aplican a la prevención, el diagnóstico y el tratamiento de enfermedades o padecimientos, así como una clasificación específica de las patologías, siendo el eje de su doctrina la sanación del cuerpo y del alma. Lo que caracteriza a este sistema médico religioso, al igual que el biomédico, es que se expresa principalmente en la categoría de integración. Ambos sostienen, como condición para obtener una mejora de la salud de la población, la necesidad de integración en la sociedad mayoritaria. Y, a cambio, el abandono de lo "tradicional" al sugerir "que las creencias han de ser transformadas" (8 p.226). Para más información sobre el porqué se otorga a la religión evangélica pentecostal la categoría de sistema médico religioso véase Ramírez $(8,12)$. El sistema médico tradicional andino "posee su propia manera de entender las enfermedades/padecimientos, y sus propias técnicas de prevención, diagnóstico y tratamiento, fundamentalmente de las patologías populares pero también de las patologías biomédicas. La interpretación de la enfermedad -así como el significado que se concede a la misma- adquiere características diferentes a las reconocidas por la iglesia evangélica y el sistema biomédico. La enfermedad es vista como un desorden de la naturaleza, como el incumplimiento de ciertas reglas o normas sociales. El origen de la enfermedad puede ser por castigo de los dioses o por un "mal" causado por otra persona o por un espíritu. Los tratamientos consisten en restablecer el orden deshecho" (8 p.167).

n. Dos iglesias de la Asamblea de Dios y una de Hermanos Libres. El trabajo de campo en las sesiones de sanación fue realizado en la iglesia más visitada por las familias informantes en casos de enfermedad. En la iglesia Asamblea de Dios se pudo presenciar 50 casos de sanación a lo largo del año.

o. Todos los nombres del artículo son seudónimos para preservar el anonimato de las personas.

p. El susto es una patología popular muy frecuente en la zona andina, causante de enfermedad y muerte. En la cultura quechua, el individuo se compone de tres almas; una de ellas es el ánimo que cuando se desprende del cuerpo provoca la enfermedad del susto. Uno de los primeros síntomas del susto es la diarrea.

q. Actualmente, debido al aumento del precio del mineral, las mujeres más jóvenes de la familia han comenzado a trabajar de palliris (limpiando el mineral) en las minas. r. El amartelo es una patología popular que aparece por añoranza de alguna persona. Es común que aparezca en los bebés cuando se les quita el pecho. El sobreparto es una patología popular que aparece por el "frío" durante o después del parto. Es considerada una de las primeras causas de muerte entre las mujeres. El orejo/orejeadura es una patología popular que aparece cuando el olor de un muerto (humano o animal) entra dentro de la persona. Es un motivo de muerte común en los niños, por ello las mujeres embarazadas evitan ir al cementerio. El estómago vacío es otra patología popular muy común en los bebés: "es cuando se da vuelta la barriga y no pueden hacer baño".

s. A partir del cuarto mes de permanencia en campo, los itinerarios terapéuticos que se pudieron presenciar fueron permanentes, cada día aparecía un caso nuevo de enfermedad o padecimiento. El número de itinerarios terapéuticos de los que se pudieron hacer seguimiento -en estas familias- fueron aproximadamente unos cincuenta y cinco, correspondientes tanto a patologías biomédicas como populares.

t. Estas falencias en el registro del dato pueden apreciarse también en países centrales, en donde la diversidad étnica es importante debido al proceso de constante migración. Tampoco esa heterogeneidad aparece reflejada en los datos epidemiológicos.

u. La mayoría de los varones no son atendidos en los centros de atención primaria pública de salud, motivo por el cual, entre otros, los varones no aparecen en dichos registros.

v. Es mayor el número de intentos de suicidio que aquellos que Ilegan a ser consumados. El suicidio en la población quechua comienza a ser realmente preocupante no solo en las zonas urbanas sino también en las áreas rurales.

w. Esto puede deberse a varios motivos: por un lado, la negación de una problemática que es cada vez mayor en el país, que se sabe pero se oculta. Por otro, las poblaciones indígenas experimentan incrementos de los casos de suicidio en las últimas décadas. La falta de perspectivas económico-sociales en la ciudad hace que los adolescentes no tengan un futuro claro, circunstancia que se añade a otros aspectos como la violencia intrafamiliar y/o el alcoholismo, que influyen sin duda en esta problemática.

x. Ch'allar es el nombre que se da al acto de compartir alcohol con la Pachamama y especialmente los mineros con el Tío. Se obsequia alcohol a la tierra con su posterior ingesta. "En Potosí, 
la Pachamama se identifica con la montaña, en cuyas entrañas maduran los minerales. Los tíos son los amos ctónicos de las minas y de las vetas, cuya explotación organizan" (17 p. 81). "Los tíos y los difuntos son asociados con el inframundo" (17 p.115).

y. Uno de los mayores problemas en la recolección de los datos cuantitativos en Bolivia, es la poca importancia que se da a cómo ha sido recogido el dato; de tal manera que se considera que una encuesta puede ser realizada por cualquiera. Un ejemplo de ello es que muchas encuestas en el país son efectuadas por el ejército, o por estudiantes de cualquier carrera, incluso de secundaria. Los datos mal recogidos terminan influyendo en la mala construcción de los mismos; como por ejemplo en el año 2001, cuando el INE daba como dato que el $90,85 \%$ de la población boliviana se declaró católica, un dato en absoluto cercano a la realidad (18).

z. La decisión de no incorporar la voz de los actores -en este artículo- se debe a que esa información ya ha sido publicada (8). aa. Mal de mina es el nombre local que se da a la silicosis. La enfermedad de la gloria aparece cuando, al caer un rayo, el humo entra dentro de la persona. El trueno asusta a la persona. Esta patología provoca tos, temperatura y debilitamiento hasta la muerte. Solo puede tratarla un terapeuta tradicional a través de una ceremonia ritual. La qayqasqa es una patología popular, considerada una enfermedad del espíritu que aparece cuando una persona duerme en lugares sagrados o en "malos lugares".

bb. Los miembros del personal sanitario no reconocen las patologías populares en el discurso que se establece con ellos en los servicios de salud. Sin embargo, sí reconocen estas patologías en sus prácticas cotidianas, es decir, cuando ejercen el rol de cuidadores de la red familiar (15).

\section{REFERENCIAS BIBLIOGRÁFICAS}

1. Scheper-Hughes N. Demografía sin números. El contexto económico y cultural de la mortalidad infantil en Brasil. En: Viola A, compilador. Antropología del Desarrollo. Teorías y estudios etnográficos en América Latina. Barcelona: Paidós; 1999. p 267-299.

2. Hammersley M, Atkinson P. Etnografía. Métodos de investigación. Barcelona: Paidós; 1994.
3. Denman C, Haro JA, compiladores. Por los rincones. Antología de métodos cualitativos en la investigación social. Sonora, México: Colegio de Sonora; 2000.

4. Guba E, Lincoln Y. Paradigmas en competencia en la investigación cualitativa. En: Denman C, Haro JA, compiladores. Por los rincones. Antología de métodos cualitativos en la investigación social. Sonora, México: Colegio de Sonora. 2000. p 113-145. 
5. Menéndez EL. Técnicas cualitativas, problemátización de la realidad y mercado de saberes. Cuadernos de Antropología Social. 2001;(13):9-51.

6. Menéndez EL. Antropología Médica. Orientaciones, desigualdades y transacciones. México DF: Cuadernos de la Casa Chata; 1990.

7. Massé R. Culture et santé publique. Les contributions de l'antropologie à la prévention et à la promotion de la santé. Montreal: Gaëtan Morin Editeur; 1995.

8. Ramírez S. Donde el viento llega cansado. Sistemas y prácticas de salud de la ciudad de Potosí. La Paz: Cooperación Italiana; 2005.

9. Instituto Nacional de Estadística. Estadísticas del Departamento de Potosí, 2005. [En línea] República de Bolivia, Instituto Nacional de Estadística, 12 de octubre de 2005 [fecha de acceso 15 de noviembre de 2008]. URL disponible en: http://www.ine.gov.bo/pdf/Est_Dptales/ Depto_2005_05.pdf

10. Instituto Nacional de Estadística. Bolivia: población por sexo y área según departamento, provincia y municipio, Censo 2001. [En línea] República de Bolivia, Instituto Nacional de Estadística [fecha de acceso 15 de octubre de 2008] URL disponible en: http://www.ine.gov.bo/indice/bd/PC20102.xls

11. Ramírez S. La interculturalidad sin todos sus agentes sociales. El problema de la salud Intercultural en Bolivia. En: Fernández Juárez G, compilador. Salud e Interculturalidad en América Latina, antropología de la salud y crítica intercultural. Ecuador: Abya-Yala; 2006. p 405-412.
12. Ramírez S. Salud, etnicidad y religión. La salud en poblaciones excluidas. Quaderns de I'Institut Catalá d`Antropología. 2006;(22):101-116.

13. Ramírez S. Entre calles estrechas. Gitanos: prácticas y saberes médicos. Barcelona: Ediciones Bellaterra; 2007.

14. Menéndez EL. La parte negada de la cultura. Relativismo, diferencia y racismo. Barcelona: Ediciones Bellaterra; 2002.

15. Ramírez S. Calidad de atención en salud. Prácticas y representaciones sociales en las poblaciones quechuas y aymaras del altiplano boliviano. La Paz: OPS/OMS. (En prensa 2009).

16. Ministerio de Salud y Deportes. Compendio de estadísticas de defunción de Bolivia: 19952001. La Paz: SNIS, OPS, Ministerio de Salud y Deportes; 2005. (Serie Documentos de divulgación científica).

17. Absi P. Los ministros del diablo. El trabajo y sus representaciones en las minas de Potosí. La Paz: IRD, IFEA, PIEB; 2005.

18. Instituto Nacional de Estadística. Nota de Prensa No 65. [En línea] República de Bolivia, Instituto Nacional de Estadística. 3 de Mayo de 2002 [fecha de acceso 15 de octubre de 2008]. URL disponible en: http://www.ine.gov.bo/pdf/ boletin/NP_2002_65.pdf

\section{FORMA DE CITAR}

Ramírez Hita S. La contribución del método etnográfico en el registro del dato epidemiológico. Epidemiología sociocultural indígena quechua de la ciudad de Potosí. Salud Colectiva. 2009;5(1):63-85.

Recibido el 2 de junio de 2008

Versión final presentada el 5 de noviembre de 2008

Aprobado el 19 de diciembre de 2008 